\title{
Moving with the Screen on Zoom: Reconnecting with Bodily and Environmental Awareness
}

Claire Loussouarn, Visiting Research Fellow, Goldsmiths University

\section{Abstract}

Rather than seeing Zoom as a replacement for practicing movement and dance in a shared physical space, I propose to consider our relationship with the screen on Zoom as a movement in its own right. Using my experience of teaching movement on Zoom, I ask how we can connect with another via the screen without losing awareness of our bodies and the space which we're in. I argue that Zoom is a place of 'moving selfies' in dialogue where we can engage critically with the screen by practicing seeing with the whole body and moving with diffuse awareness and where we can critically reflect on our own habits of framing the world and its biases.

Keywords: embodied filmmaking, environmental awareness, body awareness, multisensory perception, embodied vision, screen technology, body intelligence, amerta movement, framing, eco-somatics

Mobile devices like tablets and smartphones along with communication software such as Skype and Zoom have made it easier to engage in social activities on the go or when physically attending is not possible. This made Zoom an extremely popular choice during the Covid-19 pandemic lockdown in early 2020.300 million daily Zoom meeting participants were recorded in April 2020, a jump from 10 million at the end of 2019. ${ }^{1}$ The changes happened quite quickly because for those with access to a computer or smartphone this was the only way to continue working, practicing a hobby or socializing with friends and family. This also meant that these technological alternatives were not always the first choice of interaction.

When I first tried Zoom I felt quite resistant to it. There was something very static about it that didn't feel right. It seemed to come with the implicit rule that, to communicate, we all had to sit still, gazing at each other in front of our screens. My body felt restricted, forgotten and instrumentalized by the looking and being looked at. When I attended an Authentic Movement ${ }^{2}$ session where my body was able to move, it still felt restrictive because we were trying to do what we would normally do in a shared physical space, making it fit however we could, without acknowledging that this virtual space didn't 
function like a normal in-person gathering. Obviously Zoom has not been designed with dancers in mind. Its focus is verbally driven dialogue and it is mostly used for that. In that respect, it relies on a simplified understanding of human communication where talking heads exchange words, as depicted by Saussure's famous diagram, ${ }^{3}$ forgetting how much we rely on the co-presence of physical bodies sharing the same time and space for its full functioning, which the diagram problematically leaves out. ${ }^{4}$ Most Zoom interactions follow Saussure's model and therefore are shaped by a truncated and distorted projection of the human body in communication. ${ }^{5}$ This made me aware of two common problems when interacting on Zoom: 1) the act of seeing was limited to the eyes and the screen, forgetting that the body and its other senses all play a role in how we see and communicate; and 2) the Zoom environment was used as a replacement for physical gathering without much reflection on how social interaction and body perception are distorted through the prism of the screen.

(a)

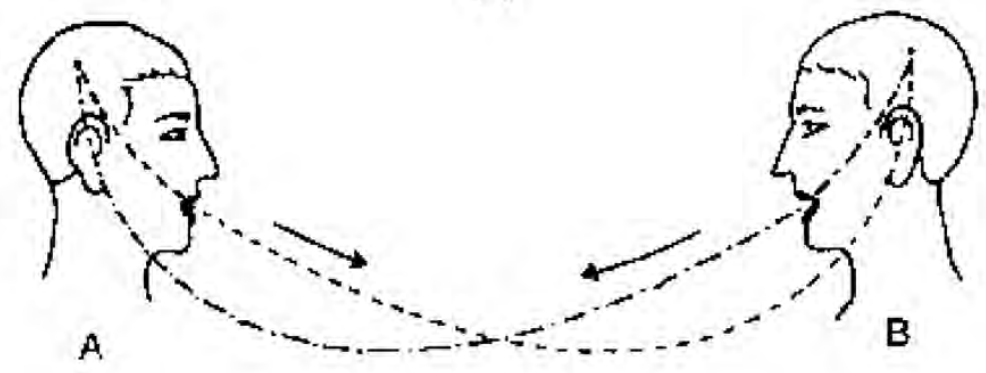

Talking heads, Saussure's model of the speech circuit. Credit: Saussure.

As a dancer, filmmaker, and screendance practitioner, I argue that it is helpful to look at Zoom not as a replacement for practicing movement and dance with others in a shared physical space but as a new way of interacting - a happy and coincidental convergence of dance and filmmaking, where we can learn to work somatically with the screen rather than ignoring it. Although this goes against existing research which demonstrates that the screen makes us more disconnected from our bodies, ${ }^{6}$ even for those who have developed body awareness over many years of somatic dance practice, ${ }^{7}$ I argue that this dissonance between the screen and the body can be reconciled by questioning our relationship to the screen as a movement practice in its own right: how can I connect with others via the screen without losing awareness of my own body and the immediate world around it? Through this article, I hope to start a discussion about the need for somatically informed critical reflection on our use of the screen, especially as the pandemic forces us to be more reliant on its use. By "somatically informed,"I mean that our bodies have an innate ability to engage critically with the limits imposed by new technologies, which can be brought to awareness by carefully investigating on its own terms "the act of awareness as a complex process" ${ }^{\prime \prime}$ through movement exploration. I 
believe those of us with a background in dance, somatic practices, and filmmaking, and those working within the field of screendance, are particularly well-placed to contribute to this conversation.

I shall be drawing on my experience of providing movement practice during the lockdown to support my argument. As a response to the unprecedented physical restrictions we were experiencing throughout 2020 and my bodily frustrations with Zoom, I decided to carry out an experiment by offering a movement class online which proposed that participants move together via the screen in its own right rather than as a way of replacing our previous experiences of moving together in the flesh. I wanted to offer a space where people could move with the physical restrictions of the lockdown, which Zoom is part of, and learn to adapt to them by finding opportunities in their limits. I invited my movement students, friends and members of the Amerta movement ${ }^{9}$ network to join. Each class was an experiment which built on the previous one as I adjusted my movement suggestions to reflect what I observed. At the beginning, the focus was on moving with the screen and our framed self-images in movement. As I observed how participants' attention shrunk more narrowly into what they could see within the screen, I moved away from this focus and decided to awaken participants' awareness of their environment and their body senses first. Then, and only then, I wove the screen in as just one element among others to move with.

I was guided in my exploration by my two main practices of embodied filmmaking and ecological somatic movement. As a dancer and filmmaker who engages with filmmaking not just as the act of looking with my eyes but with my whole body, ${ }^{10}$ I believe that the use of Zoom and screen technology is posing a similar question to the one I've been asking myself since I started filmmaking: how can I engage with the screen through which I'm connecting with another and remain connected to what I'm experiencing in my body? And as a Vipassana meditator ${ }^{11}$ and an Amerta Movement ${ }^{12}$ practitioner who has witnessed how my self-awareness is in constant motion and interdependently connected to an ever-evolving environment, ${ }^{13}$ | find myself asking the same question in relation to technology as I would when moving in a field or forest: how can I become more somatically aware of what this (virtual) environment affords and how my body receives it?

\section{'Moving selfies' in dialogue}

While Zoom liberates our communication from the constraints of time and space, it also limits it by depriving us of bodily presence with other bodies. ${ }^{14}$ Our projected image can travel through space and time but "[our] body [simply] cannot be in two places at once." ${ }^{15}$ Video-chat does a great job of allowing us to be more present in each other's lives as if we were there together in the same physical space, and therefore provides a viable solution to social distancing. German philosopher Bernhard Waldenfels refers to this as "telepresence." Ironically this likeness or "representability" to in-person social 
interaction also makes the very act of presence more difficult or rather impossible, which Waldenfels refers to as "tele-absence." ${ }^{16}$ The more immediacy the technology allows, the more we experience withdrawal in accessing this shared synchronicity of time and space. Although Zoom doesn't function like an in-person gathering, this doesn't mean that communication on Zoom is necessarily impoverished. As demonstrated by Lisa Naugle in her telematic performance Janus/Ghost Stories (1999), synchronous communication within a video-conferencing environment can be shaped into a new form by merging performers' bodies onto a fourth screen and layering choreography, visual imagery, sound, and real time video interaction. ${ }^{7}$ In a similar vein, I explore with my movement classes how Zoom offers an "entirely new situation of communication"18 which is mediated by the screen and images of ourselves in addition to verbal speech.

Although verbally driven communication is the main purpose and use of Zoom, its technological mediation inadvertently provides a new form of interaction articulated via the screen. This unintended use of the platform becomes particularly evident when practicing movement. On Zoom, we are not only dancers and performers but also film directors as well as camera operators framing and presenting our own movements on screen, with the significant difference that the film we are watching is being both made and watched at the same time. This is articulated by the self-view feature which reflects back to us and in real-time our own images, as captured by the camera of our devices, like a mirror, with the important difference that our image is not just reflected back to us but also to others who are also able to see themselves as we see them. This scenario echoes the modern phenomenon of the 'selfie' where self-images are digitally shaped within a frame knowing that they will be seen and mediated to others in this way. The Zoom self-view, like the selfie, reminds us that the making of our self-images is inherently relational and "disclose[s] not a self pathologically turned in on itself but one in which intentionality is necessarily directed elsewhere." ${ }^{19} \mathrm{On}$ Zoom, the screen doesn't just allow us to look at others; it also looks back at us. lan, ${ }^{20}$ one of the participants in my movement class, expressed that feeling after a witnessing/moving session with Emily, another participant, when suddenly she looked at the screen:

Suddenly [I] realize I'm here and I'm being addressed. The fact that it's live, there is a realization that you're in dialogue with them. It's like breaking the fourth wall in a film but more intense.

The Zoom environment, I argue, offers the unusual experience of 'moving selfies' in dialogue where filmmaking and dance converge, opening a new way to practice screendance in a more immediate and interactive manner, where the way we are framing ourselves, whether it is intentional or not, inevitably shapes how others experience our own movement and how we experience theirs. By choosing to position the screen at one angle rather than another, by deciding how to move ourselves or parts of our body in and out of the screen, or away from or closer to the screen, any participant in a movement Zoom meeting can modify the composition of the frame and therefore 
affect how their movement is perceived on screen. The Zoom self-view is, however, more immediate than the selfie. It is seen by both parties simultaneously (unless the user decides to turn their video and/or self-view off) which also means that there is no possibility to retouch and edit, or even delete, the image before it is posted online. Editing takes place through framing, what the mover decides to show within the frame, and how s/he decides to do this.

When I started the movement classes, I wanted participants to engage directly with the screen and realize that how we are seen by others and how they see us is inevitably mediated by the screen, whether we actively engage with it or not. First, I invited them to explore through movement how the screen offered a way to communicate that is similar to the language of cinema. This started with the simple exercise of choosing a frame and an angle of framing and exploring what it offers in terms of movement, i.e. how a wide shot offers the opportunity to move in the distance while still being in the frame, and how a close-up offers the possibility to move more specifically with a body part. Building up from that, participants were then invited to observe how their own movement within the physical space affects what happens on screen. The idea was to get them to somatically experience that there is a conversation going on between their self-images projected on the 2D frame of their self-view and their movement within the frame of their 3D space. For this movement invitation, I drew on my own practice of moving with the camera as an extension of my body, ${ }^{21}$ and extended it to that of moving in relation to a fixed camera angle since it is the most frequent scenario of Zoom interactions. Because I am not behind the camera and/or holding it on Zoom (unless I intentionally do so as part of my movement), it is not so much about developing a sense of where the eye of the camera is pointing, ${ }_{1}^{22}$ but more how it is projecting towards me within the 3D space. Instead of inscribing on film what I'm sensing through how I move the camera, ${ }^{23} \mathrm{I} / \mathrm{m}$ inscribing it with the movement of my body in and out of the frame. Moving in the space I' $m$ in and observing how I come in and out of the frame allows me to map out my camera's field of view and how my 3D space relates to my 2D screen. In addition, I also wanted participants to understand that what is left out of the framewhich elements of the room or body parts are excluded from the frame, or when one's body is totally off screen-also colors how others receive what is left visible on screen. In that respect, the exploration of the frame was extended to what Deleuze calls the "out-of-field," which creates meaning in relation to what is on screen. ${ }^{24}$ Participants were asked to map out the edges of the screen with their movement in order to feel how moving in and out of the frame becomes part of what they are communicating and how this also affects how they experience and move within their immediate physical space.

By getting participants to become more aware of the screen and its role of mediation on Zoom, they also became more aware of being seen and therefore that they are shaping and performing an image of themselves to others as Andrew, another class participant, reflects on: 
The class was electrifying for my introverted self. Moving in a hall, I can be certain of my indifference to audience/witnesses. Moving on Zoom with selfview on, I am immediately aware that every turn, gesture and placement of my body is both chosen and presented by me to the others watching. For, if I have not chosen and presented those things, then who? In that moment I have become, technically speaking, an unconditional extravert.

However, unlike the photographic selfie which is intentionally created as a performance of the self to be shared on social media, the moving selfie on Zoom is an unintended byproduct of the platform that not everyone is enthusiastic about or comfortable to interact with and share with others, especially since there is no room for editing or deleting one's image before it is seen by others. Its use is more ambiguous. When I invited participants in my classes to engage with the screen, I noticed a disparity in how they responded: some were quick to adapt and play with the frame, and clearly enjoyed its performative aspect to the point of getting totally sucked in. Others preferred to ignore it entirely or just shied away from it, avoiding being seen. Some just couldn't stop looking and/or engaging with the screen in a mesmerized and awkward way, somehow amazed, somehow paralyzed by it. The two pitfalls of overperforming or shying away from being seen are not uncommon in in-person movement classes, but on Zoom the screen amplified how self-conscious participants felt.

The idea in getting participants to be moving selfies was for them to become more aware of their reactions to the screen (i.e. completely absorbed or hiding from it), how this affects how they move, how it differs from other contexts in which they normally move and communicate with others and therefore how they can make a more conscious choice as to how and when, or if at all, to engage with the screen. What I hadn't anticipated is that engaging directly with the screen in this way overemphasized vision as the primary sense, and a narrow understanding of vision as focal and fixed made participants more oblivious to the way that other senses also shape their visual perception and the way they move.

\section{It is the whole body that sees, not just the eyes}

When I started the online classes, moving with awareness of the frame felt necessary to acknowledge what changes when we move virtually together in this way as opposed to within a shared physical space. However, after a few sessions it became obvious that the movers' attentions narrowed to what they could see on screen away from physical sensations and the materiality of their space. Moving primarily with the screen made participants more reliant on focal vision within the frame of the screen, as if their bodies, the surrounding space, and objects only existed on screen. In that sense, the somatic engagement with the screen that I was encouraging on Zoom echoed current research on the topic which demonstrates that the use of screen technology distracts our attention away ${ }^{25}$ and makes us less likely to be aware of what is happening around us. ${ }^{26}$ 
A dissociation seems to happen between what I'm focusing my attention on visually on screen and what my body is sensing, what I'm experiencing in my body and around it. Sokolova observed in a group of authentic movement practitioners who were asked to use the smartphone to record how they witnessed someone else move that "the majority of participants do not succeed in maintaining their bodily presence in the process." 27 Participants in my classes were no different when asked to engage with their self-view. As mentioned above, in that respect, the use of Zoom and screen technology posed a similar question to the one I've been asking myself since I started filmmaking: how can I engage with the screen through which I'm connecting with another and remain connected to what I'm experiencing in my body? I draw on my own movement practice of embodied filmmaking to show that presence is not incompatible with the screen provided we widen our awareness of seeing to the whole body.

Because a lot is going on when we widen our seeing to the whole body, my movement invitations on Zoom aim to focus on one aspect at a time so that movers can slowly become more aware of the different elements at work and how they relate to one another. I use my own practice when filming with a camera in my hands ${ }^{28}$ on Zoom for movers to become more aware of the role of the body when using the camera of their smartphone or tablet. ${ }^{29}$ In this way, I encourage participants to develop a sense of moving with the camera as a body extension without any assumption of how it should be held, and a sense of seeing what the camera is filming without looking at the viewfinder. The idea is to develop a sense of sight without relying on the eyes or focusing and therefore to trust our kinesthetic ability to see. I also argue that holding the camera is holding the future audience in my hands and that therefore I'm transmitting much more than a visual experience, that is to say, I am transmitting a kinesthetic experience via touch, movement, and framing. This means that how we hold and move the camera is equally important to what can be seen within the frame. To help participants engage with that idea I suggest that there is a little person inside the camera, and I ask them how they want this little person to feel as they're moving with their camera.

This somatic approach to the screen that I build upon here echoes and follows up on the work of dancers, performers, designers, and architects who have critically reclaimed the use of other senses in redefining our interaction with-and design of-objects, technology, and buildings, and therefore challenge the primacy of vision. ${ }^{30}$ In the West, vision is "seen" as the primary sense, underplaying the role of other senses, and therefore the whole body, in the act of perception. ${ }^{31}$ This Western and modern understanding of vision, known as "ocularcentrism," isolates "the eye outside its natural interaction with other sense modalities" and therefore "increasingly reduce[s] and restrict[s] the experience of the world into the sphere of vision." ${ }^{32}$ When working with the frame, this bias is amplified. The frame, with its restricted field, reinforces what is already a narrow understanding of vision as a fixed and focal gaze directed outward with the eyes. In the movement classes, I wanted participants to experience that this 
understanding of vision is reductive and that vision cannot be separated from the other senses. In addition to the exercise of moving with the camera without looking at the viewfinder, I therefore use simple eye movement exercises to show that the eyes find it hard to remain static or move slowly and that they, in fact, like to move very quickly and constantly, jumping from one point to the next: eye movements which are known as saccades. ${ }^{33} \mathrm{I}$ also guide them to practice unfocused and peripheral vision when moving and to generally become more aware of their tendencies in seeing, i.e. whether they tend to look close, midway, or in the distance. Beyond the eye movements, they are also invited to experience that vision involves the whole body in motion and not just the eyes, which Gibson refers as "ambient" and "ambulatory vision." 34

Once they have a more kinesthetic understanding of seeing and the eyes, I then introduce the role of the others senses in their experience of perception and how those senses are not separated from the act of seeing. I do this by inviting participants to move with one sense only, i.e. touch, sound, or proprioception, to really develop their awareness of it, and then I introduce sight while asking them to keep awareness of the other sense at the same time. This helps participants to be more aware that their seeing is inherently synesthetic, that is to say, how it is intertwined with other sensory information in the act of perception and vice versa. At the end of a movement session focused on touch, one of the participants, Dominique, enthusiastically exclaimed "I suddenly felt my eyes at the end of my fingertips!" Each participant is therefore invited to experience in their own way how their senses connect with each other, what their sensory habits are-notably which senses they tend to rely most on when movingand how to work with them. As these one-off exercises build on each other, I also complement them with a regular practice of witnessing ${ }^{35}$ another mover, a technique developed by Sandra Reeve ${ }^{36}$ as part of her teaching of Amerta Movement. The technique requires participants to adopt a non-judgmental intention and positive welcoming which is akin to the listening of a trained counsellor. ${ }^{37}$ It is carried out in pairs: each person witnesses the other move and then moves in front of the other, being witnessed by them, for the same amount of time. Because it is separating the role of mover and witness, this allows each participant to become more comfortable with being seen as well as with how their body informs their seeing. Eventually, by observing another move and our experience of witnessing at the same time, we learn to become "involved witnesses" and can apply those qualities of witnessing to ourselves when we are moving. ${ }^{38}$

The focus on vision demonstrates how much objective knowledge is culturally valued in the West ${ }^{39}$ since vision refers to the mind and the ability to acquire such knowledge through detached observation. The act of seeing is associated with a strong desire to make sense of the world and the object of our sight, to define it and fix it. ${ }^{40}$ In that sense, "vision separates us from the world."41 The practice of seeing with the whole body aims to challenge this Cartesian dualism of mind and body and therefore the idea that we can separate ourselves from the object of our perception. Peripheral vision, for example, 
enables us to broaden the role of being mere spectators (associated with focused vision) as the practice of peripheral vision "integrates us more with space." ${ }^{2}$ Because "the dominance of the eye [has suppressed] the other senses [...] to push us into detachment, isolation and exteriority," ${ }^{\prime 43}$ being more aware of how other senses shape our seeing is crucial to understanding that we are not separated from the object of our seeing but part of it. "We learn to trust our vision of the table as being there, for instance because we can always go over and touch it." ${ }^{\prime 44}$

Acknowledging that we see with our whole bodies is acknowledging that seeing is not separated from the world; it is not fixed and is much wider than focused vision. It is subjective, multi-sensory, three-dimensional, and relational. I see through the lens of my whole body in a constant evolving relationship with the environment and with what I'm seeing. It is therefore more accurate to say that our use of the screen for communication does not makes us disembodied per se but accentuates an existing lack of awareness of the role of the body in seeing stemming from a narrow understanding of vision as fixed and focal. In the next section, I will argue that acknowledging the role of the body in seeing and consciously moving with the screen in this way critically questions the dissonance between body and mind that we experience when using screen technology. As we adapt our movement practices to the Zoom environment, it is therefore useful to keep this question in mind: how can I keep the body actively involved in the act of seeing when moving with the screen?

\section{Recognizing our framing}

When we see, we are always seeing from a perspective..$^{45}$ We are receiving and making images through the lens of our whole body, its senses, its memories, its social and cultural conditioning. The screen, by constraining what we receive and communicate to a frame, is not so different from how we are always seeing and being seen through the lens of our perception. By adding another layer and making us also the filmmakers of our self-images, which are projected to ourselves and others, the Zoom environment brings more forcefully into awareness the act of framing that is already at work, but which is not as consciously visible without the use of the technology. In that sense, as Uzlaner argued about the selfie, the screen does not so much transform human nature as it reveals more fully how it works. ${ }^{46}$ While his argument focuses specifically on the gaze of the other and our desire to control it, here I am more concerned with how we cannot escape seeing through a lens despite our desire to see reality objectively.

In cinema, the frame is a "point of view." ${ }^{47}$ In that sense, it is not so dissimilar to how we see in everyday life. Although we experience what we see as fully-fledged threedimensional objects (unlike a screen which gives us a 2D flat image) we can only see them in space from the perspective of where we are at any moment: "because vision is everywhere $[\ldots]$ we as perspectival beings are able to see things from somewhere." ${ }^{\prime 48}$ 
Therefore, when we frame in filming we are already selecting and imposing a perspective on what we see, whether we acknowledge it or not. As Jean Rouch, a French ethnographic filmmaker, has argued quoting Dziga Vertov, film editing doesn't start in the editing room with the editor; it starts with framing:

The producer-cameraman of direct cinema is his own first spectator thanks to the viewfinder of his camera. All gestural improvisation (movements, centerings, duration of shots) finally leads to editing in the camera itself. We can note here again the notion of Vertov: "the 'cine-eye' is just this: I EDIT when I choose my subject [from among the thousands of possible subjects], I EDIT when I observe [film] my subject [to find the best choice from among a thousand possible observations...]."49

The role of our subjectivity is not always fully acknowledged in filmmaking and especially in documentary making where there is a common myth of objectivity which assumes that one can represent others realistically without acknowledging the subjective lens of the filmmaker. For example, framing other cultures through an inevitably biased Western lens has wrongly led some scholars to objectify them as exotic in the name of objective knowledge. ${ }^{50}$ On Zoom, there is nobody behind the camera deciding how to frame. It is up to the Zoom user to frame herself/himself or not and therefore there is no separation between the image maker and the subject. The mover has more agency over her/his own framing provided s/he wants to engage with this role and is able to articulate this within the remit of the technology and the features of the platform. Although this takes away any potential power imbalance, it doesn't take away the fact that we are still observing ourselves and each other through our own lens.

Moving somatically, that is to say with awareness, with the screen on Zoom gives us the opportunity to recognize how we frame ourselves and others in everyday life and the role that the whole body plays in it. At the same time as the frame of the screen restricts our seeing (as I discussed in the previous section), ironically it also offers the opportunity to expand our vision and therefore to reconnect with the idea of seeing with the whole body, not just with the eyes. Cinema and its language of the frame is not just visual, it is also a somatic experience based on bodily perception. ${ }^{51}$ By constraining our vision, framing invites us to reconnect with the multi-sensory experience of seeing. In The Skin of the Film, Laura Marks demonstrates how working with close-up images appeals to a haptic or tactile visuality and therefore invites a more intimate, embodied and sensory reception of the images.

The same process happens with filmmaking: we are receiving an image through the lens of our body when making it. Any images that we make carry "the imprint of our bodies." 52 There are "corporeal images [...] not just images of others" bodies [but] also images of the body behind the camera and its relationship to the world." ${ }^{53}$ To acknowledge this is to acknowledge that filmmaking is inherently embodied and therefore that the way I'm holding and moving my camera in partnership with my body 
reflects how I'm experiencing what I'm seeing through the lens of my body and how I'm transmitting this experience, through my body in movement (or stillness) and the way it is holding the camera, to a future audience. In my own work, I've described how l've used my whole body and its kinesthetic ability to listen and sense the moving body that I'm filming while inscribing my sensing through the act of filming in movement. ${ }^{54} \mathrm{As}$ explained earlier, I invited participants in my movement class to develop their sense of seeing with the whole body when moving with the camera without looking at the viewfinder or without preconceptions about how to hold the camera. In another exercise following on from that, I helped them to experience that seeing with the whole body still applies without the camera. Moving as camera bodies is a useful practice and metaphor to understand that we are moving-sensing frames ourselves which are not separated from what we are framing. The practice helps us to become more aware of our part in a wider composition and that we are in constant dialogue and co-creation with the environment. In order to guide participants to experience how they are such moving perspectives, I use body structure as a focus to start with. I invite participants to feel the shapes their bodies can make using different body parts, arrangements, and tensions. The aim is to get them to experience that the body is a shape-shifting frame which shapes what they see not just from the perspective of their eyes but also from the three-dimensionality of their whole body, which receives the world through different directions and sensory inputs. This exercise is inspired by the teaching of Suprapto Suryodarmo, who developed Amerta Movement, and more specifically his "framing practice" which asks movers to make frames with their own bodies to become more aware of their selection in seeing without losing the experience of their body in context.

While our receiving and making of images all happens simultaneously, when practicing movement on Zoom it is useful to break those two roles down: practice moving while being watched, and practice receiving movement by observing someone else move. The practice of witnessing another move described earlier allows us to become familiar with each role by focusing on one at a time with the ultimate aim of being able to combine both and therefore being able to witness oneself and one's perspective as part of a bigger composition. In turn, we are able to notice when our seeing is disconnected from the body and our surrounding environment and therefore to be more aware of this when we are moving. As I will discuss next, witnessing oneself moving is particularly challenging on Zoom where the reflection of our self-view tends to disconnect us from our body and the environment. This is why it is important not just to remain focused on the screen, our self-image, and the images of the others, but also to move with a sense of diffuse awareness that gives equal importance to our body; its sensations, thoughts, and feelings; and everything else that is around us in the environment and shaping our experience and sense of self, including the screen. 


\section{Practicing diffuse awareness with the screen}

The awareness of the gaze and its judgment about how we move on Zoom can make us self-conscious ${ }^{55}$ and/or can encourage us to over-perform in front of the screen. Focusing on the self-view, whether by performing or feeling self-conscious, creates a situation where our preoccupation with how we are moving within the frame (and therefore are being perceived by others) makes us oblivious to the environment where our own body is grounded. We might be aware of our body's reflection as an image within a frame but not actually feel our body and its physical connection to the environment it is located in. As when taking a selfie, by focusing on my self-view or others' self-views, "I remain partly oblivious to my body's role in disclosing the world around me." 56

This is because the self-view, like a mirror, reminds me that I am always the object of someone else's gaze, that "I am vulnerable, that I have a body which can be hurt, that I occupy a place and that I cannot in any case escape from the space in which I am without defense-in short, that I am seen." ${ }^{157}$ The mirror, as Lacan argued in his mirror stage theory, plays a similar role to the gaze of the other: it helps me to recognize myself as an ego, it gives shape to my identity. ${ }^{58}$ Ironically, this process of reflection creates a division between, on one hand, my image - the idea I have of myself, how I look and what I should look like-and, on the other, my body —its physical sensations and what it feels like to be that body. It privileges a Cartesian idea of seeing and what my body looks like over physical sensations, separating the idea of myself from my body. As Merleau-Ponty describes, "a Cartesian does not see himself in the mirror; he sees a dummy, an outside, which, he has every reason to believe other people see in the very same way but which, no more for himself than for others, is not a body in the flesh." ${ }^{159}$

Self-view on Zoom echoes the use of the mirror in some forms of Western dance training which objectifies the dancer's body into something that should be corrected to conform to an ideal image and proper dance technique ${ }^{60}$ creating a dividing tension between what is seen and what is felt. This becomes a situation where we focus so much on being "self-in-relation to others" via the screen that we forget that "we are [also] self-inrelation to the environment," ${ }^{61}$ a body that feels its presence in the context of its location, a body that is among the seeing. One of the class participants, Dominique, reflects:

At the beginning, I was in love with my image and it felt narcissistic but afterwards it became less important. The image of myself that I wanted to project, my avatar, wasn't so seductive anymore, it was integrated.

I'm interested in how we can experience seeing without feeling disconnected from our own bodies and the environment around us, and therefore how the two can be reconciled in our use of screen technology as Dominique describes experiencing throughout the class. As I have articulated throughout this article, my starting point is that the screen narrows down our awareness of the world to something that is focused 
and visual to the detriment of an awareness that is more encompassing of the whole and body-oriented. The screen requires a visual, focal attention, but not being able to focus visually on my body or the world around me doesn't mean that I cannot be aware of them. As Prettyman argues, "attention is a much more varied phenomenon than visual focal attention" and the concept deserves to be enriched by the less researched phenomenon of "diffuse attention." Prettyman continues:

There are numerous examples that point to the phenomenon of diffuse attention in vision and across modalities - watching a landscape, feeling the whole body, listening to the sound of a noisy room. Yet diffuse attention is difficult to operationally define, and it is not clear that it should be considered a way of attending at all, rather than a way of being diffusely aware. ${ }^{62}$

The idea of "mov[ing] with a sense of diffuse awareness-awareness of different sounds, tastes, sights and sensations; awareness of other people; awareness of our impact on our surroundings and their impact on us; awareness of our skeleton, our thoughts, our feelings, our movement ... all at the same time ${ }^{\prime 63}$ is at the heart of Amerta Movement practice. Developing this embodied awareness of my own body, the environment, and their interconnection is the first step toward noticing my habitual patterns of movement, how they are limiting me, and therefore opening myself up as a mover to new possibilities where "I can practice initiating through choice rather than the compulsion of habit." ${ }^{64}$

By acknowledging that we see with the whole body, we become more aware of our assumptions about vision, how they restrict our relationship with the screen, and how reconnecting with other body senses critically questions this limitation. Moving with a sense of diffuse awareness is the step that follows, when we embrace the vastness of our seeing, where the screen is just one element among many others, and when we can see and choose new possibilities of movement. By encouraging participants to "move with a sense of diffuse awareness," I want them to give equal value to the screen, our bodies, and our immediate environment, and to remind ourselves that we move among what we see and experience-neither externally to it nor at the center of it. Trying to keep these all in our awareness, noticing our attention's fluctuations and preferences, all form part of the practice. That way, the screen and what happens via the screen just becomes one of the many things that is happening in the environment. At times, I might give it more attention as I might give more attention to a corner of my room while remaining aware of what's around me and my body. For that purpose, it is useful to move with the self-view off and/or to switch between the two modes on and off and to notice the differences and our tendencies in either mode. I have also run a number of movement sessions in which I invited participants to vary their modes of attention: at first, ignoring the screen and focusing on awareness of their own body and movement; then gradually integrating awareness of their own movement in relation to the environment; and lastly bringing in an awareness of the screen while still keeping in 
mind awareness of the body and of its interaction with the environment. The intention here is not so much to value one more than the other but to become more aware of our preferences and of how our movement changes, if it does, when self-view is on or off or when I now bring the screen to my attention. This allows me to become more aware of how I move with the screen, how I'm limiting myself in this way, and what are the other choices at my disposal that I am less aware of. "By experiencing our changing bodies as part of a changing environment, we diminish the sense of a rigid boundary between the experience of self and that of the environment," ${ }^{165}$ which is accentuated by the screen. Through the practice of moving in this way, participants experienced a much more porous and fluid boundary between self, the other, and the world. lan observed:

The process of feeling my own body or something in the room as I was witnessing Emily move became more about the experience of what she was feeling rather than what it looked like. I was in somebody else's shoes.

Andrew likewise observed:

When I moved in the greenhouse, with the camera outside, framing myself in the partially reflective glass of the greenhouse-I suddenly dissolved. Not only was there a visual 'hall of mirrors' effect but I experienced in my solarplexus a visceral sense of dissolving. In that moment, my idea of myself also seemed to dissolve.

In summary, there is generally a narrowing of our attention to the screen, allowing us to forget that the screen is only a part of our immediate environment that serves to mediate our connection with others. Because of this, a somatic engagement with the screen, I argue, requires a refinement of "eco-somatics" as a practice which not only "encourages an equal alertness to both the inner reality of the participant and to their external environment" 66 but also to its interconnection and extension into others' environments via the screen. Although Suprapto Suryodarmo didn't extend his own teaching to include screen-mediated movement, he certainly liked to weave digital and physical worlds in this way. He famously spent much of his time on his smartphones (he often had more than one) while holding workshops. At first, one could not help but think: how can such a master of his own body be distracted in this way? The response is that he was not because he didn't make a separation between being on his phones and holding the workshop. He would find a way to attune, to recognize synchronicities, and to weave whatever was happening on another continent via his phone with what was happening in the workshop. ${ }^{67}$ For Suryodarmo, the two could not be separated and were considered to be part of the same reality. They needed to be woven together in the same way that he would recognize the importance of the physical environment in how we move. This weaving of physical and virtual environments, I argue, is fundamental to a movement practice on Zoom which reconciles the screen and bodily awareness. 


\section{Conclusion: building a somatic relationship with new technology}

Whereas, at first sight, transferring our dance practices to videoconferencing software like Zoom can feel like a second best that can never fully replace moving together in the flesh, it also offers, I argue, an opportunity to move with the screen with more awareness and to critically question our physical relationship with it. Because of the challenges it presents in limiting our connection with the body, Zoom forces us to question and redefine our bodily interaction with the screen so that becoming aware of our own body and its interaction with the environment, of which the screen is just one element, is crafted at the heart of it. First, it is important to bring to awareness and experience through movement how the act of seeing is grounded in the whole body and its senses, especially when working on Zoom where a biased and restricted understanding of vision is reinforced by the screen. Second, seeing is not just visual and focal, it is also diffuse and multi-sensory. It is therefore particularly useful to practice diffuse awareness when moving with the screen as it allows us to remain equally aware of our body, the environment we are moving in, the screen, the other environments we are connecting with virtually via the screen, and how we are in constant flux, shaping and being shaped, dialoguing with and weaving together all these different elements.

I have shown that bodily presence and the use of screen technology are not incompatible per se. This requires us to see that moving with new technologies is a movement practice in its own right. With my movement classes on Zoom and a discussion of this exploration of the screen through movement, I am responding to Kolcio's call for "encourag[ing] physical engagement and awareness" 68 when bringing new technology directly into practical application. I argue, using Zoom as an example, that our movement practices need to acknowledge and reflect what the screen affords as much as what it limits. My work therefore connects to and affirms how artists and performers question the limits of technology within the context of performance, while expanding the question outside the performance context. The field of telematic dance is particularly relevant to the context of my argument as it explores how videoconferencing environments such as Zoom offer new forms of communication and being together by extending our experiences of space and time. MacCallum and Naccarato's concept of "critical appropriation" emphasizes the value of critically questioning the use of objects and technology outside the remit of their intended use. ${ }^{69}$ And lastly, the work of dance artist Isabelle Choinière, who is purposefully imposing limits with new technologies in choreographic propositions to expand the performer's perception by forcing her/him to reorganize it, is particularly relevant to my approach. ${ }^{70}$ While Choinière intentionally destabilizes the body with the use of technology to enhance the potential for corporeality in performance, her aim has much in common with what I am advocating here: that there is a creative opportunity in asserting our bodily intelligence when engaging critically with the physical constraints imposed by new technology. 
While this work is directly relevant to how we adapt performance and dance practices online, it also allows us to question and redefine our use of the screen in everyday life. Emily, one of the regular attendees of my classes, felt inspired to re-explore video-chat and suggested to her friends that they have 20-minute non-verbal video calls with her: "video calling felt like we were always trying to find enough to say, while never being truly present with each other or able to be vulnerable." In that respect, the increased use of screen technology in lockdown is an opportunity for us dancers and screendance filmmakers to offer a critical reflection on what the screen affords and limits not just in the context of performance and dance practices, but also beyond, within our daily movement and interaction with others via the screen. What's more, seeing creative opportunities in the limits of technology also invites us to challenge the way dance and technology are often opposed ${ }^{71}$ and therefore to reassert the relevance that "the present body that we live has an 'intelligence' of its own" 72 which already has the necessary tools to learn to adapt to new technologies. The idea of my movement classes on Zoom is in that respect not to create a specific set of techniques that allows us to work within the specificities of this virtual environment. It is to help movers to reflect on their sensory and movement habits with and without the screen as two contrasting modes and therefore to reconnect with their body intelligence when moving via the screen to find their own way to remain embodied with it.

\section{Acknowledgements}

I would like to thank all the participants in my Zoom movement classes who made rich and insightful contributions. Without them this article would not have been possible. I would also like to thank Dominique Rivoal for suggesting I write it and for providing thoughtful and constructive criticisms to the first draft, Sandra Reeve for providing supportive and clarifying feedback to a very early draft, and Andrew Carey for support with editing. Lastly, I would like to thank the two reviewers of this article who made insightful comments and helped to push and improve the articulation of my thinking on this question.

\section{Biography}

Claire is a social anthropologist, filmmaker and movement artist. She is a Visiting Research Fellow at Goldsmiths, University of London, where she researches on ecological movement, mindful movement, embodied filmmaking, screen technology and the feral body. She is co-founder and co-curator of Kinesthesia, a moving image festival which focuses on the multi-sensory experience of filmmaking and watching films. She is currently working on a durational visual art installation in collaboration with 
filmmaker and researcher Dominique Rivoal which explores ecological dialogue with the non-human by moving every month in the same spot in Hackney Marshes in London over the course of several years. She is writing a book about the feral body as a radical tool of being and thinking beyond the limits of our anthropomorphic and anthropocentric view of the world.

Email: loussouarn.claire@gmail.com

Website: www.claireloussouarn.com

\section{Notes}

1 Daily meeting participant is different from daily active user as they "can be counted multiple times: if you have five Zoom meetings in a day then you are counted five times." Zoom doesn't provide daily active user statistics. https://www.theverge.com/2020/4/30/21242421/zoom-300-million-users-incorrectmeeting-participants-statement

${ }^{2}$ Authentic Movement is a somatic dance practice where the mover has his/her eyes closed and focuses inwardly, observing body sensations, images and feelings that arise, while being witnessed.

${ }^{3}$ Saussure, Cours de Linguistique Générale.

${ }^{4}$ See Meyer, Streeck \& Stock, Intercorporeality; and Thomsen, "From Talking Heads to Communicating Bodies."

${ }^{5}$ See Lanier, "Virtually there"; Lee, "A Psychological Exploration of Zoom Fatigue"; Friesen, "Telepresence and Tele-absence"; and Wiederhold, "Connecting Through Technology," 437.

${ }^{6}$ See Gazzaley and Rosen, The Distracted Mind; and Hyman et al., "Did You See the Unicycling Clown?"

${ }^{7}$ Sokolova, "The Smartphone as Witness."

${ }^{8}$ Kolcio, "A somatic engagement of technology," 104.

${ }^{9}$ Amerta or Joged Amerta movement is an ecological somatic practice developed by Suprapto Suryodarmo, a Javanese movement artist and teacher. One of its characteristics is that it "pays attention to environmental embodiment and attaches crucial importance to the mutual interdependence and co-creation of organism and environment." Reeve, "Reading, Gardening and 'Non-Self,"' 190. 
${ }^{10}$ Loussouarn, "Dancing with Nature Off the Leash" and "Dancing with the camera."

${ }^{11}$ Vipassana is a meditation technique which focuses on observing sensations, scanning carefully each part of your body with equanimity, that is to say without giving more importance to pain or pleasure.

${ }^{12}$ See note 9 above.

${ }^{13}$ Reeve, "The Next-Step: Eco-somatics and Performance."

${ }^{14}$ See Lanier; Friesen, "Telepresence and Tele-absence."

${ }^{15}$ Friesen, "Telepresence and Tele-absence," 22.

${ }^{16}$ Ibid.

${ }^{17}$ Naugle, "Distributed Choreography."

${ }^{18}$ Ferencz-Flatz, "Ten theses on the reality of video-chat," 219.

${ }^{19}$ Bollmer and Guinness, "Phenomenology of the Selfie," 169.

${ }^{20}$ All quoted participants gave permission to the author to be referred by their first names.

${ }^{21}$ Loussouarn, "Dancing with Nature Off the Leash"

22 Ibid.

${ }^{23}$ Loussouarn, "Dancing with the camera."

${ }^{24}$ Deleuze, Cinema 1, 18.

${ }^{25}$ Gazzaley and Rosen.

${ }^{26}$ Hyman et al.

27 Sokolova, 132.

${ }^{28}$ See Loussouarn, "Dancing with Nature Off the Leash" and "Dancing with the camera."

${ }^{29}$ Or even laptop, which offers some degree of mobility.

${ }^{30}$ See Loussouarn, "Dancing with Nature Off the Leash" and "Dancing with the camera"; Kozel, Closer; Loke and Pohl, "Engaging the sense of touch"; MacCallum and Naccarato, "Critical Appropriations" and "The Touch of the Stethoscope"; and Schiphorst, "Soft(n)."

${ }^{31}$ See Belova, "The Event of Seeing"; Jay, "The Rise of Hermeneutics"; Marks, The Skin of the Film; and Pallasmaa, The Eyes of the Skin.

${ }^{32}$ Pallasmaa, 39. 
${ }^{33}$ See Jay, 311; Gibson, The Perception of the Visual World.

${ }^{34}$ Gibson, The Ecological Approach to Visual Perception.

${ }^{35}$ Although the practice of witnessing shares much with Authentic Movement, I discuss it more specifically in relation to the way Sandra Reeve teaches it.

${ }^{36}$ Sandra Reeve is a movement artist and teacher who studied extensively for many years with Suprapto Suryodarmo and has been a well-known and accomplished teacher of Amerta Movement for more than 30 years. She has developed her own unique style of teaching Amerta.

${ }^{37}$ Sandra Reeve refers to Carl Roger's concept of "unconditional positive regard."

${ }^{38}$ Personal communication with Reeve, 7 August 2020.

${ }^{39}$ Ingold, 283

${ }^{40}$ Pallasmaa.

${ }^{41}$ Ibid. 25.

42 Ibid. 13.

${ }^{43}$ Ibid. 19.

${ }^{44}$ Gibson, The Perception of the Visual World, 223.

${ }^{45}$ Ibid.

${ }^{46}$ Uzlaner, "The Selfie and the Intolerable Gaze of the Other."

${ }^{47}$ Deleuze, 15.

${ }^{48}$ Suhr and Willerslev, "Can Film Show the Invisible?" 286.

${ }^{49}$ Rouch, "The Camera and Man." Emphasis and brackets in Rouch.

${ }^{50}$ Trinh, "Documentary Is/Not a Name."

${ }^{51}$ See Barker, The Tactile Eye; Luke Hockley, Somatic Cinema; and Marks.

${ }^{52}$ MacDougall, The Corporeal Image, 3.

${ }^{53}$ Ibid.

${ }^{54}$ Loussouarn, "Dancing with the camera."

${ }^{55}$ This is more the case with less experienced movers and beginners. With time and through the experience of being witnessed in a safe and non-judgmental manner by other movers, this lessens. This is also one of the goals of the practice of witnessing as 
taught by Sandra Reeve: to invite us to move without feeling petrified or that there is an expectation of having to perform.

${ }^{56}$ Bollmer and Guinness, 168.

57 Sartre, Being and Nothingness, 259.

${ }^{58}$ Uzlaner.

${ }^{59}$ Merleau-Ponty, "The Eye and the Mind," 170.

${ }^{60}$ Green, "Somatic Authority."

${ }^{61}$ Reeve, "The Next-Step," 6.

${ }^{62}$ Prettyman, "Attention and Conscious Perception," 51-52.

${ }^{63}$ Reeve, "Reading, Gardening and 'Non-Self,'" 200-201.

${ }^{64}$ Ibid. 195

${ }^{65}$ Ibid. 194

${ }^{66}$ Reeve, "The Next-Step," 6

${ }^{67}$ Personal communication with Reeve, 7 August 2020.

${ }^{68}$ Kolcio, 122.

${ }^{69}$ MacCallum and Naccarato, "Critical Appropriations."

${ }^{70}$ Choinière, "For a methodology of transformation."

${ }^{71}$ Kolcio.

72 Parviainen, "Bodies Moving and Moved," 30.

\section{References}

Barker, Jennifer. The Tactile Eye: Touch and the Cinematic Experience. Berkeley: University of California Press, 2009.

Belova, Olga. "The Event of Seeing: A Phenomenological Perspective on Visual Sense$\begin{array}{lllll}\text { Making," } \quad \text { Culture and Organization. } 12.2 & \text { (2006): }\end{array}$ https://doi.org/10.1080/14759550600682866 
Bollmer, Grant and Katherine Guinness. "Phenomenology of the Selfie." Cultural Politics 13. 2 (2017): 156-176. https://doi.org/10.1215/17432197-4129113

Choinière, Isabelle. 'For a methodology of transformation at the crossroads of somatics and technology: Becoming another...,' Journal of Dance and Somatic Practices 5.1 (2013): 95-112. https://doi.org/10.1386/jdsp.5.1.95_1

Deleuze, Gilles. Cinema 1: The Movement-Image. Minneapolis: University of Minnesota Press, 1986.

Ferencz-Flatz, Christian. "Ten theses on the reality of video-chat: a phenomenological account." Communications 44.2 (2019): 204-224. https://doi.org/10.1515/commun2018-2012

Friesen, Norm. The Place of the Classroom and the Space of the Screen. New York: Peter Lang, 2011.

---. "Telepresence and Tele-absence: A Phenomenology of the (In)visible Alien Online." Phenomenology \& Practice 8.1 (2014): 17-31. https://doi.org/10.29173/pandpr22143

Gazzaley, Adam and Larry D. Rosen. The Distracted Mind. Cambridge: MIT Press, 2016.

Gibson, James. The Perception of the Visual World. Westport: Greenwood Press, 1974 (originally published in 1950).

---. The Ecological Approach to Visual Perception. New York: Taylor \& Francis Group,1986.

Green, Jill. "Somatic Authority and the Myth of the Ideal Body in Dance Education." Dance Research Journal 31.2 (1999): 80-100. https://doi.org/10.2307/1478333

Hockley, Luke. Somatic Cinema: The Relationship between Body and screen - A Jungian perspective, London: Routledge, 2013.

Hyman, Ira E., S. Matthew Boss, Breanne M. Wise, Kira E. McKenzie, and Jenna M. Caggiano. "Did You See the Unicycling Clown? Inattentional Blindness while Walking and Talking on a Cell Phone." Applied Cognitive Psychology 24.5 (2009): 597-607. https://doi.org/10.1002/acp.1638

Ingold, Tim. The Perception of the Environment: Essays in Livelihood, Dwelling and Skill, London: Routledge, 2000.

Jay, Martin. "The Rise of Hermeneutics and the Crisis of Ocularcentrism." The Rhetoric of Interpretation and the Interpretation of Rhetoric 9.2 (1988): 307-326. https://doi.org/10.2307/1772691

Kolcio, Katja. "A somatic engagement of technology." International Journal of Performance Arts and Digital Media 1.2 (2005): 101-125. 
Kozel, Susan. Closer: Performance, Technologies, Phenomenology. Cambridge: MIT Press, 2007. https://doi.org/10.7551/mitpress/9780262113106.001.0001

Lanier, Jaron. "Virtually there: Three dimensional teleimmersion may eventually bring the world to your desk." Scientific American 284.4 (2001): 66-75. https://www.cs.unc.edu/Research/ootf/inthenews/pdf/sciam_2001_0401.pdf

Lee, Jena. "A Psychological Exploration of Zoom Fatigue." Psychiatric Times. 27 July 2020. Accessed 21 August 2020. https://www.psychiatrictimes.com/view/psychologicalexploration-zoom-fatigue

Loke, Lian and Ingrid Maria Pohl. "Engaging the sense of touch in Interactive Architecture." Proceedings of the $24^{\text {th }}$ Australian Computer-Human Interaction Conference. 2012. 493-496. https://doi.org/10.1145/2414536.2414611

Loussouarn, Claire. "Dancing with Nature Off the Leash." Botanical Drift: Economic Botany and its Plant Protagonists. Ed. Khadija von Zinnenburg. Berlin: Sternberg Press, 2017. 64-68.

---. "Dancing with the camera." Somatics Toolkit for Ethnographers. 2019. http://somaticstoolkit.coventry.ac.uk/loussouarn-dancing-with-the-camera.

MacCallum, John and Teoma Naccarato. "Critical Appropriations of Biosensors in Artistic Practice." Proceedings of the 4th International Conference on Movement Computing. 2017.

---. "The Touch of the Stethoscope: Shaping context in Intimate Performance." Tempo 73.287 (2019): 71-75. https://doi.org/10.1017/S0040298218000669

MacDougall, David. The Corporeal Image: Film, Ethnography and The Senses. Princeton: Princeton University Press, 2006. https://doi.org/10.1515/9781400831562

Marks, Laura. The Skin of the Film: Intercultural Cinema, Embodiment and the Senses. Durham: Duke University Press, 2000. https://doi.org/10.1215/9780822381372

Merleau-Ponty, Maurice. "The Eye and the Mind." The Primacy of Perception, and Other Essays on Phenomenological Psychology, the Philosophy of Art, History, and Politics. Ed. James E. Edie. Evanston, IL: Northwestern University Press, 1964.

Meyer Christian, Streeck Jürgen \& Stock Jordan J. Intercorporeality: Emerging Socialities in Interaction. New York: Oxford University Press, 2017. https://doi.org/10.1093/acprof:oso/9780190210465.001.0001

Naugle, Lisa Marie. "Distributed Choreography: A Video-Conferencing Environment." Journal of Performance and Art 71 (2002): 56-62. https://doi.org/10.1162/152028102760049328 
Nedergaard Thomsen, Ole. "From Talking Heads to Communicating Bodies: Cybersemiotics and Total Communication." Entropy 12 (2010): 390-419. https://doi.org/10.3390/e12030390

Pallasmaa, Juhani. The Eyes of the Skin: Architecture and the Senses. Chichester: WilleyAcademy, 2005.

Parviainen, Jaana. "Bodies Moving and Moved: A Phenomenological Analysis of the Dancing Subject and the Cognitive and Ethical Values of Dance Art." PhD Thesis, Tampere University Press, 1998.

Prettyman, Adrienne. "Attention and Conscious Perception." PhD Thesis, University of Toronto, 2014, https://central.bac-lac.gc.ca/.item?id=TC-OTU65560\&op=pdf\&app=Library\&oclc_number $=1033020603$

Reeve, Sandra. "The Next-Step: Eco-somatics and Performance." The Changing Body Symposium. University of 2005. https://www.moveintolife.com/uploads/1/3/9/6/13969833/the_changing_body2.pdf

---. "Reading, Gardening and 'Non-Self': Joged Amerta and its emerging influence on ecological somatic practice." Journal of Dance and Somatic Practices 2.2 (2010): 189-203. https://doi.org/10.1386/jdsp.2.2.189_1

Rouch, Jean. "The Camera and Man." Principles of Visual Anthropology. Ed. Paul Hockings. De Gruyter, 1995. 79-98.

Sartre, Jean-Paul. Being and Nothingness: A phenomenological essay on ontology, New York: Washington Square Press, 1993.

Saussure, Ferdinand de. Cours de Linguistique Générale. Paris: Payot, 1916.

Schiphorst, Thecla. "Soft(n): Towards a Somaesthetics of Touch." Proceedings of the Conference on Human Factors in Computing Systems. April 2009. 2427-2438, https://doi.org/10.1145/1520340.1520345

Sokolova, Elena. "The Smartphone as Witness: Technological Mediation of Bodily Sensory Experience." Forum for Anthropology and Culture 15 (2019): 116-136.

Suhr, Christian and Rane Willerslev. "Can Film Show the Invisible? The Work of Montage in Ethnographic Filmmaking." Current Anthropology 53.3 (2012): 282-301. https://doi.org/10.1086/664920

Trinh Minh-ha. "Documentary Is/Not a Name." October 52 (1990): 76-98. https://doi.org/10.2307/778886

Uzlaner, Dmitry. "The Selfie and the Intolerable Gaze of the Other." International Journal of Applied Psychoanalytic Studies 14.4 (2017): 282-294. https://doi.org/10.1002/aps.1525 
Wiederhold, Brenda K. "Connecting Through Technology During the Coronavirus Disease 2019 Pandemic: Avoiding 'Zoom Fatigue'" Cyberpsychology, Behavior and Social Networking 23.7 (July 2020): 437-438. https://doi.org/10.1089/cyber.2020.29188.bkw 